\title{
Down-regulation of miR-27a might inhibit proliferation and drug resistance of gastric cancer cells
}

\author{
Xiaohong Zhao ${ }^{*}$, Li Yang ${ }^{*}$ and Jianguo Hu
}

\begin{abstract}
Aims: Here we aimed to firstly investigate the role of miR-27a in proliferation and multidrug resistance of gastric cancer cells.

Methods: The role of miR-27a in gastric cancer cells was detected using MTT assay, soft agar assay, flow cytometry assay, nude mice assay, real-time PCR, western blot and reporter gene assay, etc.

Results: Down-regulation of miR-27a could inhibit porliferation of gastric cancer cells in vitro and in vivo. Downregulation of miR-27a could also confer sensitivity of drugs on gastric cancer cells, and might increase accumulation and decrease releasing amount of adriamycin in gastric cancer cells. Down-regulation of miR-27a could significantly decrease the expression of P-glycoprotein and the transcriptional activity of cyclin D1, and upregulate the expression of p21.
\end{abstract}

Conclusions: MiR-27a might play important roles in porliferation and drug resistance of gastric cancer. MiR-27a might be considered as a useful target for cancer therapy.

Keywords: miR-27a drug resistance, porliferation, gastric carcinoma

\section{Introduction}

Gastric cancer was one of the major causes of mortality in the world, especially in Asian countries. So far, the pathogenic mechanism underlying gastric carcinogenesis was not fully elucidated.

MicroRNAs (miRNAs) were a class of 22-nucleotide noncoding RNAs, which might function as regulators of gene expression [1]. More and more evidences showed that miRNAs might play important roles in various biological processes, including cell proliferation, apoptosis, tumorigenesis and MDR of cancer [2]. So far, the functions of gastric cancer related miRNAs were not clear. MiR-27a might mediate drug resistance of esophageal cancer cells through regulation of MDR1 and apoptosis [3]. However, the role of miR-27a in gastric cancer was not reported yet. To our knowledge, here we have firstly investigated the role of miR-27a in proliferation and multidrug resistance of gastric cancer cells.

\footnotetext{
* Correspondence: ningxiaxiaohong@126.com; ningxiayangl@126.com Institute of Digestive Disease, Subsidary Hospital, The Medical University of Ningxia Province, Yin'chuan, 750001, Ningxia Province, China
}

\section{Materials and methods \\ Cell culture}

Human gastric cancer cell line, MKN45, was routinely maintained in DMEM medium (GIBCO, Carlsbad, CA, USA) supplemented with $10 \%$ fetal bovine serum at $37^{\circ}$ $\mathrm{C}$ in humidified air containing $5 \%$ carbon dioxide air atmosphere.

\section{MiRNA transfection}

Cells were plated in plates and cultured for $16 \mathrm{~h}$, and then transfected with the antagomirs of miR-27a or control RNA (Lafayette, CO) as described previously [3].

\section{Real-time PCR}

Total RNAs from cells were extracted and cDNA synthesis and amplification were performed as described previously [4]. Primers were designed as: MDR1, forward: 5'-CCCATCATTGCAATAGCAGG-3', reverse: 5'TGTTCAAACTTCTGCTCCTGA-3'; cyclinD1, forward: 5'-GGAGCTGCTCCTGGTGAACA-3', reverse: 5'TGTTGGGGCTCCTCAG GTTCA-3'; P21, forward:

\section{Ciomed Central}

(c) 2011 Zhao et al; licensee BioMed Central Ltd. This is an Open Access article distributed under the terms of the Creative Commons Attribution License (http://creativecommons.org/licenses/by/2.0), which permits unrestricted use, distribution, and reproduction in any medium, provided the original work is properly cited. 
5'-CCCGTGAGCGATGGAACT-3', reverse: 5'-CGAGGCACAAGGG TACAAGA-3'; P27, forward: 5'-CAAGTACGAGTGGCAAGAGG-3', reverse: 5'-GTAGAA GAATCGTCGGTTGC-3'. Comparative real-time PCR was performed in triplicate, including no-template controls. Relative expression was calculated using the comparative Ct method.

\section{Cell growth assay}

Cells were seeded on a 96-well plate at $3 \times 10^{4}$ cells/well. Each sample has four replicates. Viable cells were counted by the MTT assay after 2, 4, 6, and 8 days.

\section{Soft agar assay}

Soft agar assay was performed as described previously [5]. Each assay was performed in triplicate.

\section{Tumor growth in nude mice}

Female athymic $n u / n u$ mice, 5-6 weeks of age, were used in the experiment. The cells were resuspended in D'Hanks solution, and $5 \times 10^{6}$ cells in $0.2 \mathrm{ml}$ were injected subcutaneously into the right flank of 4-weekage mice. Experimental and control groups had at least 6 mice each. Tumors were measured twice weekly, and the tumor volume was calculated.

\section{In vitro drug sensitivity assay}

Vincristine (VCR), adriamycin (ADR), cisplatin (CDDP) and 5-fludrouracil (5-flu) were prepared before experiment. Drug sensitivity was evaluated using MTT assay as described previously [3].

\section{Flow cytometry assay (FCM)}

Fluorescence intensity of intracellular ADR was detected by FCM as described previously [3].

\section{Western blot}

Cellular proteins were separated on SDS-PAGE gels, and western blot was performed as described previously [3].

\section{Reporter gene assay}

The pGL3-cyclin D1 vector and the control vector were prepared as described previously [3]. Briefly, $0.4 \mu \mathrm{g}$ of reporter gene constructs was transfected into MKN45 cells using LipofectAMINE (Invitrogen) reagent according to the manufacturer's protocol. This transfection was done concurrently with the transfection of the antagomirs of miR-27a. Cells co-transfected with scrambled antago-miR-NC served as controls.

\section{Statistical analysis}

All the data were presented as the mean $\pm \mathrm{SD}$. The significance of differences was determined with Student's $t$ test or the $\chi 2$ test. $P<0.05$ was considered statistically significant.

\section{Results}

Down-regulation of miR-27a inhibited the growth and tumorigenecity of gastric cancer cells

As Figure 1A showed, MKN45 cells were transfected with either the antagomirs of miR-27a or control RNA. The antagomirs of miR-27a could significantly inhibit the expression of miR-27a by almost $67 \%$ as compared with that of control. Cell growth was assayed, and down-regulation of miR-27a significantly inhibited proliferation of MKN45 cells as compared with control ( $<$ < 0.05) (Figure 1B). MKN45 cells and their transfectants were seeded in soft agar and colon formation was assessed. As shown in Figure 1C, down-regulation of miR-27a significantly inhibited the number of colonies formed by gastric cancer cells. Tumorigenesis was found profoundly decreased in miR-27a-downregulating cells as compared with control groups (Figure 1D), suggesting that down-regulation of miR-27a might inhibit the growth of MKN45 cells in vitro and in vivo.

\section{Down-regulation of miR-27a might reverse drug resistance of gastric cancer cells}

As shown in Table 1, the IC50 values of miR-27a antagomir cells for VCR, ADR and 5-flu were significantly decreased as compared with control cells. The ADR intracellular accumulation and releasing were explored using FCM assay. As shown in Figure 2A, B, increased accumulation and decreased releasing index of ADR of miR-27a antagomir cells was observed as compared with control cells $(\mathrm{p}<0.05)$.

\section{Effect of mir-27a on protein regulating proliferation and drug resistance}

The expression of P-glycoprotein, cyclin D1, p21 and p27 was detected in the gastric cancer cells using real-time PCR (Figure 3) and western blot (Figure 4). Down-regulation of miR-27a could significantly decrease the expression of Pglycoprotein and cyclin D1, and up-regulate the expression of p21. To evaluate whether cyclin D1 was a genuine target of miR-27a, luciferase reporter assay was performed. As shown in Figure 5, co-transfection of increasing amounts of antagomirs of miR-27a with cyclin D1 reporter gene led to significantly decrease in cyclin D1 promoter activity, suggesting that miR-27a might target cyclin D1.

\section{Discussion}

Aberrant miRNA expression patterns had been described in a variety of malignancies. MiRNAs might play important roles in multiple developmental processes. MiR-27a was widely expressed in cancer cells and might function 


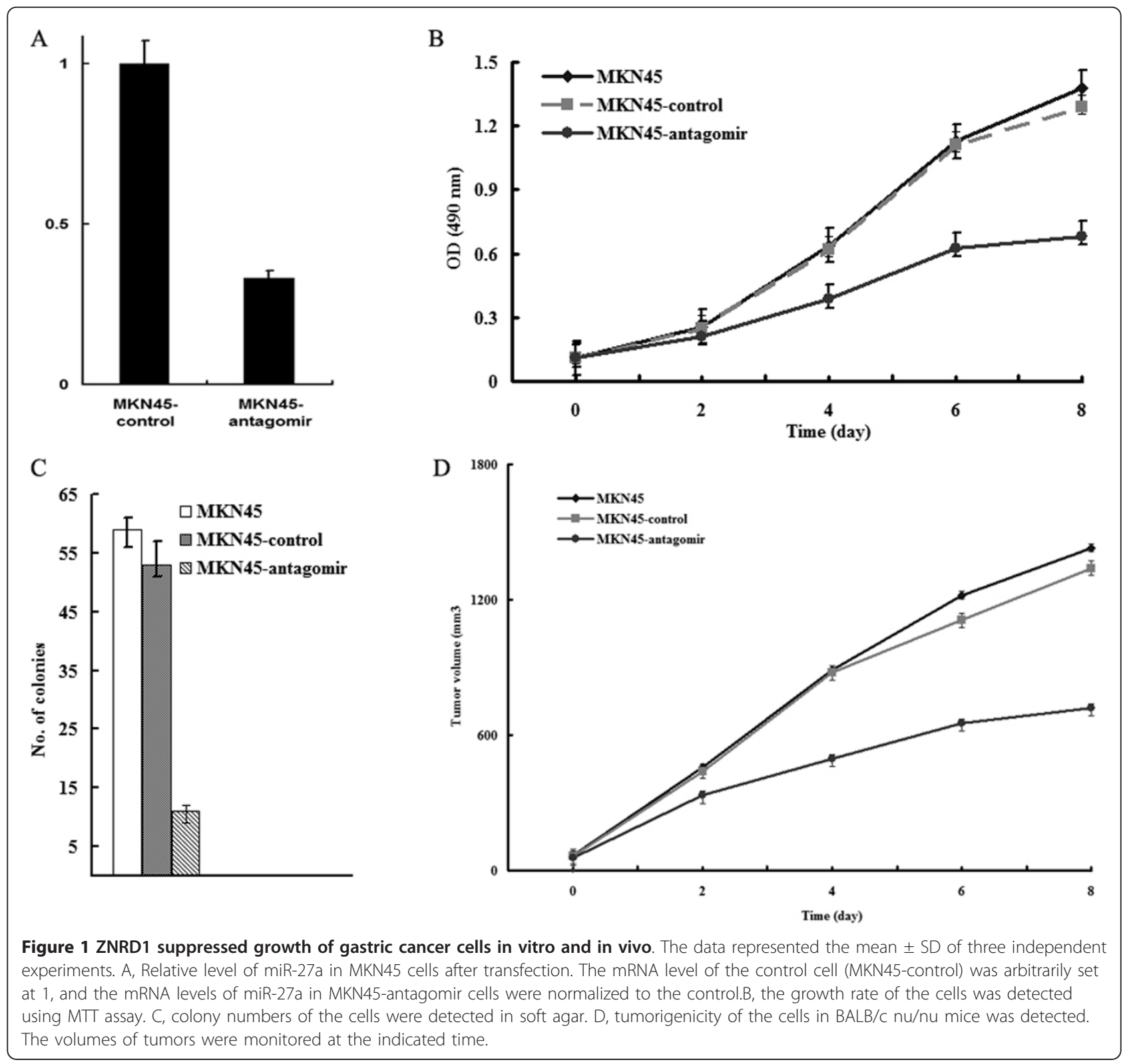

as an oncogene through regulating cell survival and angiogenesis [6-11]. In this study, we have firstly found that miR-27a might play important roles in mediating proliferation and drug resistance of gastric cancer.

To obtain a better model in which cells of the same origin could be compared, we transfected MKN45 cells with the antagomirs of miR-27a or control RNA. The results of MTT assay and soft agar assay revealed that down-regulation of miR-27a inhibited cell growth of gastric cancer cells in vitro, which was consistent with the data of nude mice assay. The study was aimed at investigating the effect of miR-27a on gastric cancer cells and more importantly, examining the mechanisms governing these effects. Here we clearly showed for the

Table 1 IC50 values $(\mu \mathrm{g} / \mathrm{mL})$ of drugs for gastric cancer cells

\begin{tabular}{lcccc}
\hline & VCR & ADR & 5-Flu & CDDP \\
\hline MKN45 & $6.12 \pm 0.22$ & $6.41 \pm 0.15$ & $5.24 \pm 0.11$ & $5.11 \pm 0.13$ \\
MKN45-control & $5.81 \pm 0.16$ & $6.22 \pm 0.11$ & $4.88 \pm 0.15$ & $4.38 \pm 0.26$ \\
MKN45-antagomir & $1.68 \pm 0.11^{\mathrm{a}}$ & $1.93 \pm 0.12^{\mathrm{a}}$ & $1.79 \pm 0.08^{\mathrm{a}}$ & $1.16 \pm 0.07^{\mathrm{a}}$ \\
\hline
\end{tabular}

Data were represented as mean \pm SD of 3 independent experiments. ${ }^{a} p<0.05$ vs MKN45 and MKN45-control cells. 


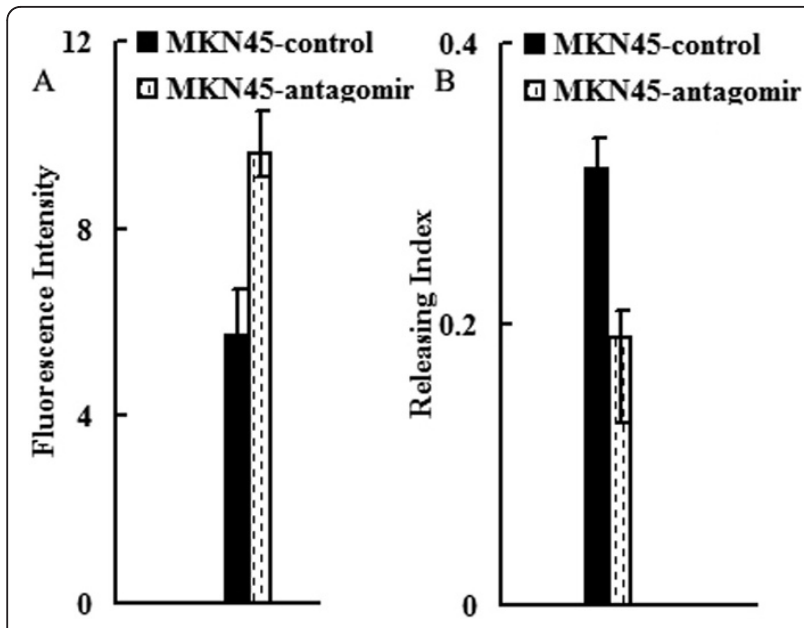

Figure 2 Effect of miR-27a on ADR intracellular accumulation and releasing of MKN45 cells. A, Fluorescence intensity analysis of intracellular ADR in cells; B, ADR releasing index of cells.

first time that miR-27a might mediate cell proliferation by regulation of cyclin D1 and p21. Cyclin D1 might play important roles in facilitating the transition from $G_{1}$ phase into $S$. The results of luciferase reporter assay suggested that miR-27a might be a transcriptional regulator of the cyclin D1 gene.

The results of MTT assay indicated that down-regulation of miR-27a promoted drug sensitivity of gastric cancer cells. ADR was then used as probe to evaluate drug accumulation and retention in cancer cells. The results of FCM showed that down-regulation of miR-

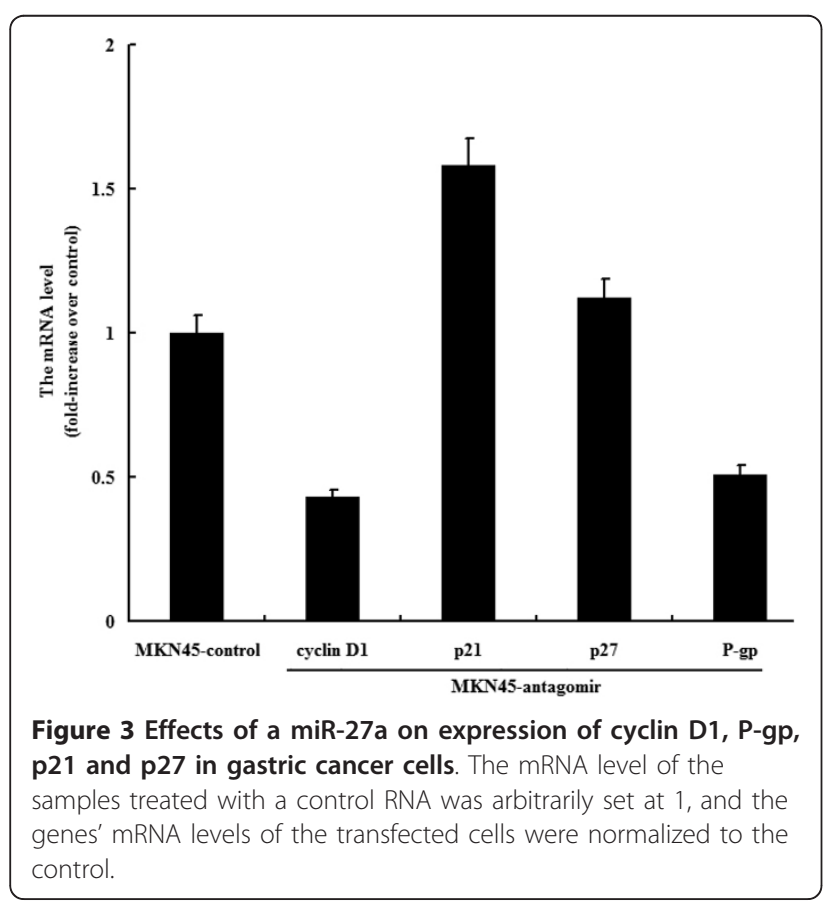

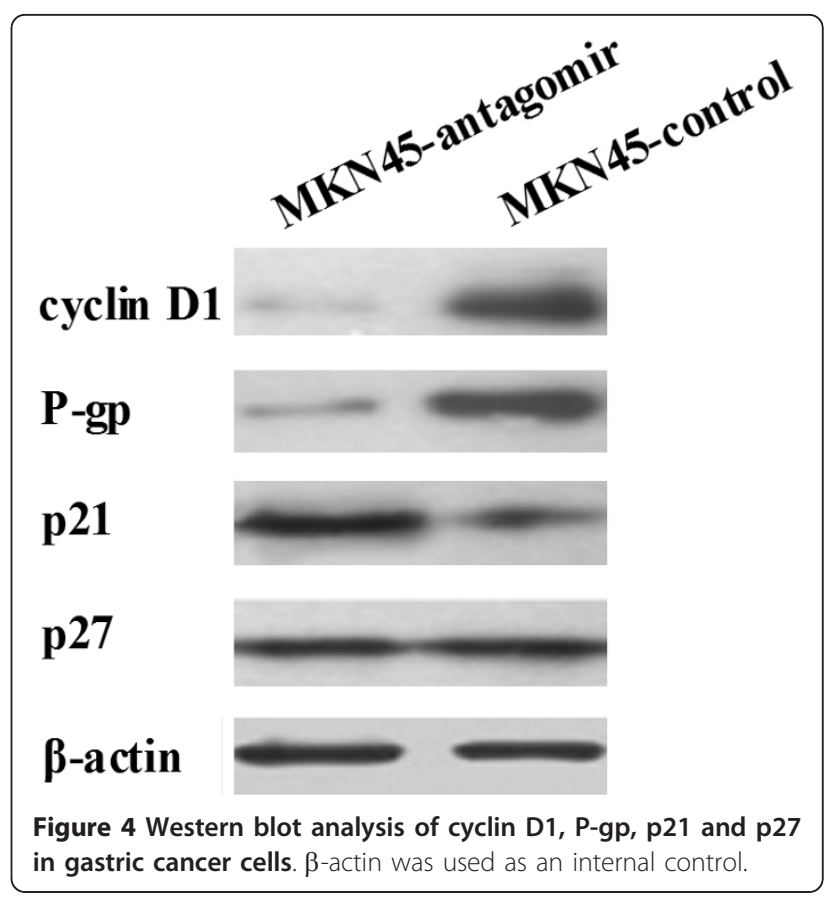

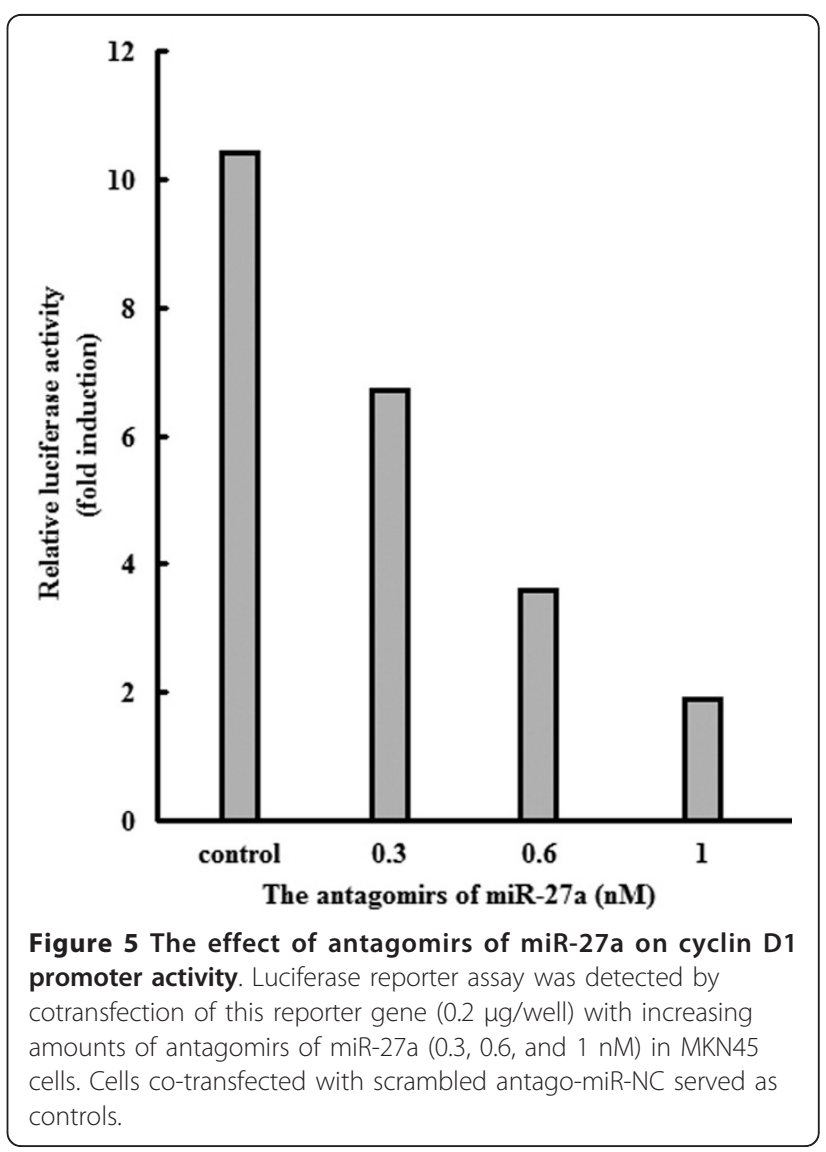


27a increased ADR accumulation and retention and decreased ADR releasing index, indicating that miR-27a had a direct or indirect function of pumping drug out of cells. The results of real-time PCR and western blot showed that miR-27a might mediate the expression of P-gp, which might function as an ATP-dependent drugefflux pump.

\section{Conclusions}

In conclusion, down-regulation of miR-27a might inhibit proliferation and drug resistance of gastric cancer cells through regulation of P-gp, cyclin D1 and p21. MiR-27a might be considered as a valuable target for cancer therapy.

\section{Acknowledgements}

This study was supported in part by grants from the National Scientific Foundation of China (30770635).

\section{Authors' contributions}

ZX and YL have made substantial contributions to conception and design, acquisition of data, and writing the manuscript. HJ participated in its design and gave final approval of the version to be published. All authors read and approved the final manuscript.

\section{Competing interests}

There is no conflict of interest. The authors declare that they have no competing interests.

Received: 7 February 2011 Accepted: 13 May 2011

Published: 13 May 2011

\section{References}

1. Bhardwaj A, Singh S, Singh AP: MicroRNA-based Cancer Therapeutics: Big Hope from Small RNAs. Mol Cell Pharmacol 2010, 2(5):213-219.

2. Kurokawa R: Long noncoding RNA as a regulator for transcription. Prog Mol Subcell Biol 2011, 51:29-41.

3. Zhang H, Li M, Han Y, Hong L, Gong T, Sun L, Zheng X: Down-regulation of miR-27a might reverse multidrug resistance of esophageal squamous cell carcinoma. Dig Dis Sci 2010, 55(9):2545-51.

4. Nishi H, Ono K, Horie T, Nagao K, Kinoshita M, Kuwabara Y, Watanabe $S$, Kimura T: MicroRNA-27a regulates beta cardiac myosin heavy chain gene expression by targeting thyroid hormone receptor $\{$ beta\}1 in neonatal rat ventricular myocytes. Mol Cell Biol 2011, 31(4):744-55.

5. Ma Y, Yu S, Zhao W, Lu Z, Chen J: miR-27a regulates the growth, colony formation and migration of pancreatic cancer cells by targeting Sprouty2. Cancer Lett 2010, 298(2):150-8.

6. Allen DL, Loh AS: Posttranscriptional mechanisms involving microRNA27a and b contribute to fast-specific and glucocorticoid-mediated myostatin expression in skeletal muscle. Am J Physiol Cell Physiol 2011, 300(1):124-37.

7. Sun Q, Gu H, Zeng Y, Xia Y, Wang Y, Jing Y, Yang L, Wang B: Hsa-mir-27a genetic variant contributes to gastric cancer susceptibility through affecting miR-27a and target gene expression. Cancer Sci 2010, 101(10):2241-7.

8. Li ZM, Hu S, Xiao L, Wang J, Cai J, Yu LL, Wang ZH: Expression of microRNA 27a and its correlation with drug resistance in human ovarian cancer A2780/Taxol cells. Zhonghua Fu Chan Ke Za Zhi 2010, 45(5):372-5.

9. Li Z, Hu S, Wang J, Cai J, Xiao L, Yu L, Wang Z: MiR-27a modulates MDR1/ P-glycoprotein expression by targeting HIPK2 in human ovarian cancer cells. Gynecol Oncol 2010, 119(1):125-30.

10. Li X, Mertens-Talcott SU, Zhang S, Kim K, Ball J, Safe S: MicroRNA-27a indirectly regulates estrogen receptor $\{a \mid p h a\}$ expression and hormone responsiveness in MCF-7 breast cancer cells. Endocrinology 2010, 151(6):2462-73.
11. Kim SY, Kim AY, Lee HW, Son YH, Lee YS, Kim JB: miR-27a is a negative regulator of adipocyte differentiation via suppressing PPARgamma expression. Biochem Biophys Res Commun 2010, 392(3):323-8.

doi:10.1186/1756-9966-30-55

Cite this article as: Zhao et al:: Down-regulation of miR-27a might inhibit proliferation and drug resistance of gastric cancer cells. Journal of Experimental \& Clinical Cancer Research 2011 30:55.

\section{Submit your next manuscript to BioMed Central and take full advantage of:}

- Convenient online submission

- Thorough peer review

- No space constraints or color figure charges

- Immediate publication on acceptance

- Inclusion in PubMed, CAS, Scopus and Google Scholar

- Research which is freely available for redistribution 